\title{
The prevalence of lateral incisors microdontia in students with Down syndrome
}

\author{
Nadia Mohammad Aziz*, Rudy Hartanto*, Williyanti Soewondo* \\ *Departement of Pedodontics Faculty of Dentistry Universitas Padjadjaran
}

\section{ABSTRACT}

Introduction: The term microdontia is used when the teeth are smaller than normal. It is recognized clinically as teeth having a usual crown shape or sometimes with tapering (peg or conical) crown in lateral incisors. Microdontia is usually manifested in systemic diseases and syndromes especially Down syndrome. The cause of microdontia is unknown but it could be multifactorial. The purpose of this research was to determine the prevalence of microdontia in patients with Down syndrome. Methods: Type of research is descriptive survey. The sampling method is purposive sampling. A study was conducted in 38 Down syndrome patients, aged between 7-29 years of age, consisted of 19 males and 19 females. The teeth were examined visually. Result: a total of 23 students had microdontia of lateral incisors of either the upper or lower jaw which indicated a prevalence of $60.53 \% .10$ students had microdontia of lateral incisors involving the upper and lower jaw which gives out a prevalence of $26.31 \%$. Overall, the total prevalence of microdontia in the students with Down syndrome was $86.84 \%$. Conclusion: Prevalence of microdontia in lateral incisors among patients with Down syndrome in Kota Bandung is high. There is no statistically significant difference in microdontia prevalence between female and male Down syndrome students.

Keywords: Microdontia, Down syndrome, conical shape.

\section{IINTRODUCTION}

The term microdontia is used when teeth are smaller than normal (i.e. outside the usual limits of variation). ${ }^{1}$ In the generalized form, all teeth are involved. In the localized form, only a few teeth are involved. The most common teeth affected are the upper lateral incisors and third molars. Microdontia is often limited to just one or two teeth. ${ }^{1}$

Down's syndrome is a syndrome caused by chromosomal abnormality in which there is an extra chromosome 21. It is a multisystem disease which has several dental aspects of interest to the dental practitioner and many underlying problems which may influence dental management. ${ }^{2}$ Past investigations of Down's syndrome (DS) have indicated that there are marked abnormalities in many aspects. These abnormalities include facial development, dental development, periodontal (gum) disease, orthodontic issues and behavioral modifications. $^{3}$

There are various dental abnormalities that can be found in patients with Down syndrome. Some patients can have extra large baby teeth, they can have teeth of varying sizes from side-to-side and they can have teeth that are fused together. The crowns of the teeth can have an odd shape or poor enamel formation. ${ }^{3}$ Approximately $35-55 \%$ of DS patients have extra small teeth (microdontia)

Corresponding author: Williyanti Soewondo, Department of Pedodontics, Faculty of Dentistry Universitas Padjadjaran, Indonesia. Jalan Sekeloa Selatan I, Bandung, West Java, Indonesia, 40132; Phone: +6222-2504985/2532805 
and $10 \%$ out of microdontia in patients with DS involve the lateral incisors which are peg-shaped. ${ }^{3}$ A report by Baird and Sadovnick in 1989 as quoted by Pilcher ${ }^{4}$ in her article, indicated that over half the individuals born with Down syndrome live into their 50 's, $40 \%$ into their 60 's and $13 \%$ to the age of 68.4 Therefore, the need for dental care in persons with Down syndrome is increasing with this inclusive trend. ${ }^{4}$

Most dental treatment for persons with Down syndrome can take place in a general dental office with relatively minor adaptations. In undergraduate dental training, there is usually little or no exposure to treating patients with disabilities, and general practitioners may be hesitant to treat these patients with confidence. ${ }^{4}$

Hence, it is important for dentists to be aware of the type of anomalies especially in the areas of the head and neck which are part of the typical developmental pattern of people with Down syndrome, which have influence on dental problems. ${ }^{5}$ Research of microdontia, especially microdontia involving the lateral incisors has a lot of importance.

The lateral incisors are part of the anterior tooth and if microdontic will affect the aesthetical appearance of the Down syndrome patient. Other than that, smaller than normal lateral incisors will cause diastema in the patient which leads to food impaction and might cause caries and gingivitis and also affect the aesthetics in this patient. Furthermore, diastemas usually distort pleasing smile by diverting observer's attention to these spaces instead of overall composition of the facial features. ${ }^{6}$

With early detection of microdontia, this enables prompt and proper treatment planning for the child with Down syndrome. The aim of treatment is to provide adequate function and restore aesthetic appearance. Ideally, for social reasons, the treatment should begin at around 2-3 years of age. ${ }^{7}$ Therefore, the writer feels that it is important to collect the data of microdontia prevalence among patients with Down syndrome as a form of early detection. This will allow early and without delay treatment and management of teeth in patients with Down syndrome.

Besides that, due to the rise in a number of Down Syndrome patients not just in Indonesia but also around the world, this has made the writer interested in doing a research about the prevalence of microdontia among patients with Down syndrome here in Kota Bandung. Another reason why the writer is keen on doing this research is due to the fact that not many studies regarding the prevalence of microdontia especially among patients with Down syndrome have been conducted here in Indonesia.

The results of this research are useful as additional microdontia prevalence data for dentistry which is highly related to the dental development in patients with Down Syndrome for better understanding when treating patients with Down Syndrome. The purpose of this research was to determine the prevalence of microdontia in patients with Down syndrome.

\section{METHODS}

The type of research conducted is descriptive to determine the prevalence percentage of microdontia in patients with Down syndrome studying in various SLB-C institutions in Kota Bandung. The research population involves all patients with Down syndrome in various SLB-C institutions in Kota Bandung who fulfill the inclusion criteria as stated below. The various SLB-Cs include SLB-C YPLB, SLB-C Plus YPLB Asih Manunggal, SLB-C Yayasan Terate Bandung, SLBMuhammadiyah, SLB-BCYPLAB, SLB-Aditya Grahita.

The sampling method is purposive sampling. The inclusion criteria of the sample include the sample taken for this research are Down syndrome patients ranging from 6-29 years of age, patients were screened by name to determine that they are indeed having Down syndrome and to determine their gender and age respective by referring to records provided by the schools, no previous restorative reshaping or crowning of the lateral incisors, no previous history of lateral incisors extraction.

The exclusion criteria include patient has missing lateral incisors, informed consent has not been given by respective parents or teacher in charge, the patient is unwell and refused to be examined. Sample and subject involve all of the population that fulfill the inclusion criteria and do not have exclusion criteria as stated above. 
RESULTS

This research was done to determine the prevalence of microdontia in patients with Down syndrome studying in various SLB-C institutions located in Kota Bandung in June 2011. 38 samples of patients with Down syndrome were collected and processed to determine microdontia prevalence. Based on the research that was conducted, the result from the data is presented in following tables and Figures as shown below.

Table 1. shows gender distribution and amount of patients studied at respective SLB-C institutions involved in this research. In this study, the total number of samples that were taken for this research is 38 patients.

These samples are those that fall within the sample selection criteria stated in the research methodology chapter of this research. Based on selection criteria, the sample of this research included patients with Down syndrome studying in various SLB-C institutions. Out of the 38 patients, 19 where male and 19 were female.

According to the pie Figure above it can be found that out of the 38 respondents, a total of 19 people or $50 \%$ of them are female and 19 or $50 \%$ of

Table 1. Distribution of Gender and Amount of Patients at respective SLB-C institutions in Kota Bandung

\begin{tabular}{llll}
\hline School & Male & Female & Total patients \\
\hline SLB-C Asih Manunggal & 4 & 2 & 6 \\
SLB-C Yayasan Teate & 4 & 3 & 7 \\
SLB-C Cipaganti & 4 & 7 & 11 \\
SLB-Muhammadiyah & 2 & 4 & 6 \\
SLB-BC YPLAB & 2 & 2 & 4 \\
SLB-Aditya Grahita & 3 & 1 & 4 \\
\hline Total & 19 & 19 & 38 \\
\hline
\end{tabular}

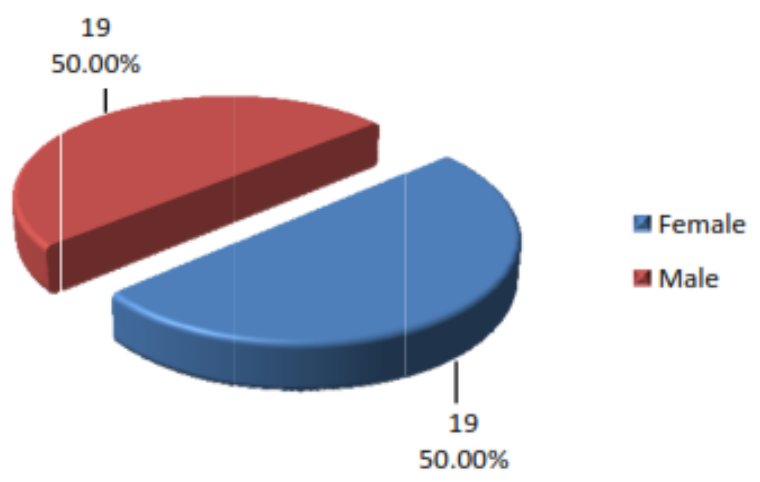

Figure 1. Population percentage according to gender the remaining sample are male. These samples are those that fall within the sample selection criteria stated in the research methodology chapter of this research.

Based on selection criteria, the sample of this research included patients with Down syndrome studying in various SLB-C institutions.

Table 2 showed the overall microdontia prevalence in patients with Down syndrome in patients with Down syndrome at various SLB-C institutions in Kota Bandung. Out of the 38 patients, 33 patients had microdontia of lateral incisors which gives a prevalence percentage of

Table 2. Overall microdontia prevalence in patients with Down syndrome in patients with Down syndrome at various SLB-C institutions in Kota Bandung

\begin{tabular}{|c|c|c|c|}
\hline $\begin{array}{l}\sum \text { Down } \\
\text { syndrome } \\
\text { patients with } \\
\text { normal } 12\end{array}$ & $\begin{array}{l}\sum \text { Down } \\
\text { syndrome } \\
\text { patients with } \\
\text { microdontia } \\
\text { of } 12\end{array}$ & $\begin{array}{l}\Sigma \text { Down } \\
\text { syndrome } \\
\text { patients }\end{array}$ & $\begin{array}{l}\text { Total } \\
\text { microdontia } \\
\text { prevalence } \\
(\%)\end{array}$ \\
\hline 5 & 33 & 38 & 86.84 \\
\hline
\end{tabular}

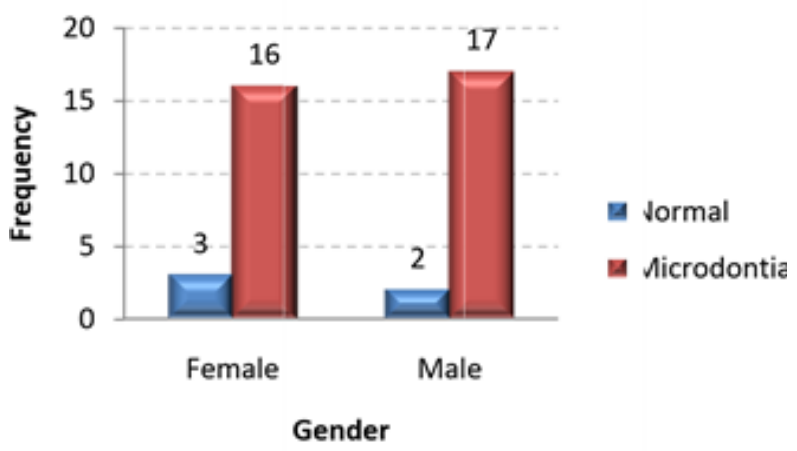

Figure 2. Frequency of microdontia according to gender distribution

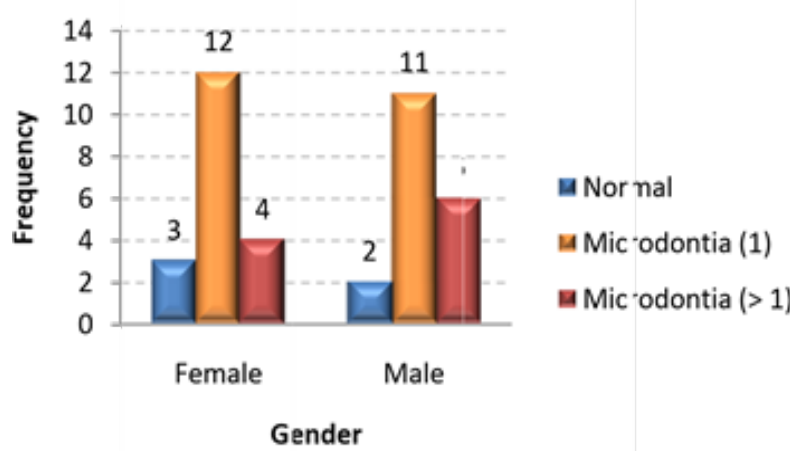

Figure 3. Microdontia according to gender and lateral incisors that are microdontic according to number jaw affected 


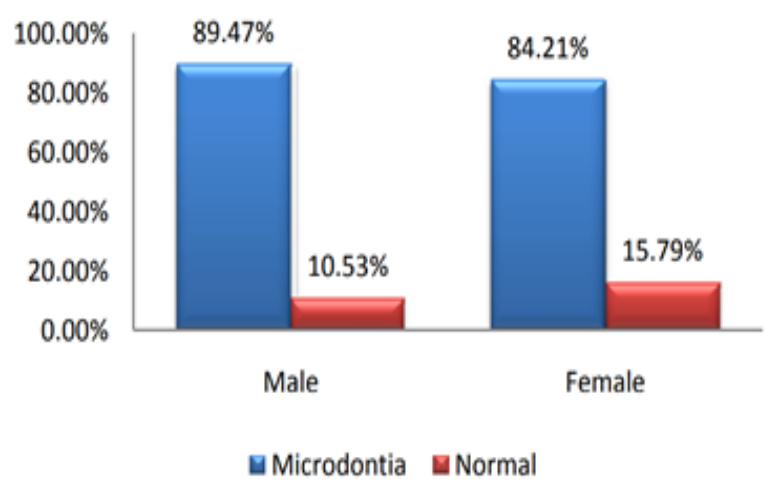

Figure 4. Microdontia prevalence in patients with Down Syndrome in various SLB-C institutions in Kota Bandung according to gender

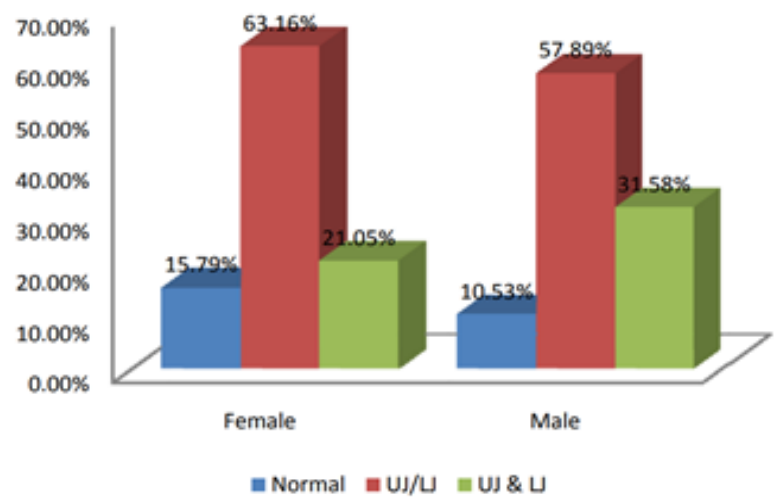

Figure 5. Microdontia prevalence according to gender and the number of jaws affected

\begin{tabular}{|c|c|c|c|c|c|c|}
\hline \multirow[t]{2}{*}{ Gender } & \multicolumn{4}{|c|}{$\begin{array}{c}\text { Prevalence of } \\
\text { microdontia }\end{array}$} & \multicolumn{2}{|c|}{ Total } \\
\hline & & ormal & & odontia & & \\
\hline & $f$ & $\%$ & $f$ & $\%$ & $f$ & $\%$ \\
\hline & 3 & 15.79 & 16 & 84.21 & 19 & 100 \\
\hline & 2 & 10.53 & 17 & 89.47 & 19 & 100 \\
\hline Pearson Chi-square & & & & & 0.23 & \\
\hline $\begin{array}{l}\text { Asymp. Sig. } \\
\text { (2-sided) }\end{array}$ & & & & & 0.63 & \\
\hline
\end{tabular}

Table 3. Show the prevalence of microdontia according to gender and its chi-square value

$86.84 \%$

The bar Figure above shows that out of the total research sample, 3 are females with normal lateral incisors, 2 are males with normal lateral incisors, 16 females had microdontic lateral incisors and 17 males had microdontia of lateral incisors.

Based on Figure 3, out of the total research sample, 3 of the females had normal lateral incisors, 2 males had normal lateral incisors,
12 females had microdontia of lateral incisors involving either upper or lower jaw, 11 males had microdontia of lateral incisors involving either upper or lower jaw, 4 females had microdontia of lateral incisor involving both the upper and lower jaw and 6 males had microdontia of lateral incisor involving both the upper and lower jaw.

Figure 4 shows the microdontia prevalence in patients with Down syndrome in various SLB-C institutions according to gender. The microdontia prevalence for the male sample was $89.47 \%$ whereas $84.21 \%$ was found in the female sample. A total of $15.79 \%$ of female patients had normal lateral incisors whereas a total of $10.53 \%$ of male patients had normal lateral incisors.

Figure 5. shows the microdontia prevalence according to gender and the number of jaws affected, Out of the 19 female patients 3 or $15.79 \%$ are categorized as having normal lateral incisors, 12 or $63.13 \%$ are categorized as having microdontia of either the upper jaw or lower jaw, and 4 or $21.05 \%$ have microdontia of lateral incisors of both upper and lower jaws.

Out of the 19 female patients, 2 or $10.53 \%$ are categorized as having normal lateral incisors, 11 or $57.89 \%$ are categorized as having microdontia of either the upper jaw or lower jaw, and 6 or $31.58 \%$ have microdontia of lateral incisors of both upper and lower jaws.

Comparison of microdontia prevalence between male Down syndrome patients and female down syndrome patients were calculated using the chi-square method (. From the calculation, Due to the smaller value of $\times 2$ calculation compared to the $x 2$ from the table $(0.230<3.841)$ and $p$-value larger than alpha $(0.631>0,05)$, hence $\mathrm{HO}$ is accepted while $\mathrm{H} 1$ is rejected.

This means that the proportion of female Down syndrome patients with normal lateral incisors is equal to proportion of male Down syndrome patients with normal lateral incisors or proportion of female Down syndrome patients with microdontia of lateral incisors is equal to proportion of male Down syndrome students with microdontia of lateral incisors, or in other words, there is no significant microdontia prevalence difference between female Down syndrome patients and male Down syndrome patients. 


\section{DISCUSSION}

Based on this research, the overall microdontia prevalence in Down syndrome patients is $86.84 \%$ which can be stated belonging to a higher range based on previous researches. This higher prevalence in this research may be due to the larger sample used in this research and the known fact of delayed development in Down syndrome patients. The prevalence of microdontia especially in lateral incisors in Down syndrome patients is highly related to the genetic abnormality present in patients with this syndrome. The presence of conical lateral incisors in patients with Down syndrome is due to the abnormal presence of an extra chromosome 21 .

In this condition, the extra genetic material causes delays in the way a child develops physically and mentally. The various delayed development of a patient with Down syndrome includes the variability of oral and tooth development, (i.e abnormalities of tooth eruption, structure, and form). Examples of delayed development of the oral cavity include variability in tooth sizes such as microdontia and macrodontia and variability of tooth numbers such as hypodontia and anodontia. In cases of microdontia, there is a disturbance in morphodifferentiation stage of tooth development. This leads to an imperfect form and shape of the tooth which is smaller in mesiodistal measurement.

Microdontia happens as a result of disturbance during tooth bud stage, which causes an obstruction of dental lamina and leads to a disturbance of proliferation from future ameloblasts (enamel-forming cells) and odontoblasts (dentine-forming cells). Disturbance of cell proliferation especially ameloblast causes less enamel matrix which leads to the formation of an abnormally small tooth. ${ }^{8}$

According to previous research, Desai et al ${ }^{9}$ reported that $35 \%$ of patients with Down syndrome have an abnormal shape with a smaller than normal lateral incisors which leads to diastema. In a prior study conducted in SLB-Cs in Kota Bandung by Willyanti Syarif from the pedodontic department of Universitas Padjadjaran in 1997, $60.60 \%$ of Down syndrome patients of ages between 18-90 months of age exhibited microdontia of lateral incisors in the upper or lower jaw or both jaws which affects both the lateral and permanent lateral incisors. ${ }^{10}$

In another study by Bhowate R. et al ${ }^{11}$ showed that a prevalence percentage of microdontia was $40.7 \%$. Results of another research by Sharath A. et al showed that $15.6 \%$ of the sample had microdontia. Therefore, the percentage of microdontia incidence in this research is $86.84 \%$ which can be stated belonging to a higher range based on previous researches. ${ }^{12}$

In the study conducted also in Kota Bandung by Willyanti Syarif in 1997, the deciduous lateral incisors were observed in the research as compared to the permanent lateral incisors observed during this research.10 It can be temporary concluded that if a patient has microdontic deciduous lateral incisors, the patient will have microdontic permanent lateral incisors. However, more research should be done to prove this hypothesis.

Based on previous researches, Tongkoom et $\mathrm{al}^{13}$ reported that microdontia was the most common dental anomaly which occurred in 6.3\% of the children.However, there was no statistically significant difference in dental anomalies between girls and boys except for hypodontia and hyperdontia. Another study done by Ezoddini et al in 2007 reported that $49.1 \%$ of male patients had dental anomalies compared to the $33.8 \%$ of females in which microdontia and germination are more frequent in women. ${ }^{14}$

Another theory by Laskaris also stated that microdontia occurs more commonly in females compared to males.15 Based on this research, it was concluded that there were no statistically significant differences in the prevalence of microdontia among male and female students. This may be due to the difference of the research subject's race in this research as compared to races of previous researches. Therefore, it is possible that gene expression differs from other races used in previous research. Hence, the result of this research differs from previous research by Ezoddini et al and Laskaris. ${ }^{14,15}$

In certain patients, there was only 1 lateral incisor present in either the upper jaw or lower jaw as the contralateral lateral incisor is either missing or is a radix. Patients with missing lateral incisors were not used as research subjects. However, students with lateral incisor present with its contralateral radix were used as research subjects. 
It can be assumed that the tooth was a radix due to the effect of tooth hypoplasia. In hypoplasia, there is a lack of development or defective development of the enamel of tooth before its eruption. In deciduous teeth, enamel hypoplasia can be caused by a disturbance in enamel formation before birth. In permanent teeth, enamel hypoplasia can be caused after birth since enamel formation of permanent dentition occurs after birth. According to Shafer (2009), an unusual type of hypoplasia is when only a single tooth is involved (commonly the maxillary incisors) as seen in this research. ${ }^{16}$

A conical lateral incisor is a manifestation of severe hypoplasia while in mild cases it involves abnormalities in pits and grooves. The tooth that is moderately or severely affected may show a tendency for wear and fracture of enamel or in other words, it is easily decayed and is prone to fracture. This might be the cause of contralateral radix in this research.

Another possible reason for the presence of radix in this research is due to the unilateral chewing of the Down syndrome patient. Unilateral chewing by the patient may be due to hypotonia (decreased in muscle tone), a typical feature of Down syndrome. Muscular hypotonia is one of the clinical signs in patients with Down syndrome and is clearly evident in the face expression and oral dysfunction.

Patients with Down syndrome may find it hard to chew, suck and swallow food especially for a prolonged period of time. A patient might face difficulty chewing using both sides of the mouth, hence opting to chew only on 1 side. This might be the possibility of the patient retaining a tooth on 1 side with a radix on the other as seen in this research. Another matter observed during this study is that some patients were cooperative and some were not. This might have a connection with the IQ condition of the patient. It can be theorized that a more cooperative patient may possess a higher IQ compared to a non-cooperative or less cooperative patient. It is safe to conclude that a higher IQ in a Down syndrome patient means that the patient is suffering from a milder version of Down syndrome. In the case study by Dr. Willyanti, a patient with full trisomy suffers a higher prevalence of microdontia of $69.7 \%$ compared to patients with mosaic trisomy.
This supports the theory by Lowitz and Mark, Desai that abnormalities in the mosaic type are milder compared to a patient with full trisomy. Hence, it is safe to conclude that patients with Mosaic trisomy has a better prognosis compared to patients with Full trisomy. Based on this research, the 5 patients with normal lateral incisors were most cooperative while the Down syndrome patients that had microdontia of withering upper or lower jaw, in general, were cooperative. The patients with microdontia of both upper and lower jaw were seen to be less cooperative compared to other patients.

There were uncooperative in certain ways such as refusing to open their mouths to be examined and will lie down on the ground refusing to be examined. In this study, the age of subjects taken was between ages of 6-29 years of age. The eruption of permanent upper lateral incisors is during ages between $7-8$ years of age. ${ }^{17}$ Hence, the lateral incisors observed during this research study are the permanent lateral incisors. The age of the subjects is seen according to their mental age and not the normal physical growth and development age. The IQ range of a patient with Down syndrome is between 20-85 with a mean IQ of approximately 50. ${ }^{17}$ However, their IQ rarely exceeds $60 .{ }^{18}$ Due to this fact, all Down's syndrome patients in this research were used as subjects. Limited research time and unpredictable attendance of students were also problems faced during the research.

\section{CONCLUSION}

Prevalence of microdontia in lateral incisors among patients with Down syndrome in Kota Bandung is high. There is no statistically significant difference in microdontia prevalence between female and male Down syndrome students.

\section{REFERENCES}

1. Kahn, Michael A. Basic Oral and Maxillofacial Pathology. Volume 1. 2001.

2. Seagriff-Curtin P, Pugliese S, Romer M. Dental considerations for individuals with Down syndrome. NY State Dent J 2006;72(2):33-5.

3. Mueller., James. 2010. Genetic Disorders. Available online at http://geneticsf.labanca. net/?p=497 [Cited 22 May 2011] 
4. Pilcher ES. Dental care for the patient with Down syndrome. Down Syndrome Research and Practice 1998;5(3):111-6.

5. Loh IM. Dental Problems in People with Down's Syndrome. Understanding Intellectual Disability and Health. Available from:www. intellectualdisability.info/physical-health/ dental-problems-in-peoplewith-downssyndrome [Cited 10 Mar 2011). 2011.

6. Naisargi S, Jyoti N, Tulika K. Restoring Maxillary Lateral Incisors with Ceramic Laminate Veneers: An Esthetic Challenge. Internat J Prosthtic Dentistry. 2010:1(1):15-16.

7. Cameron AC, Richard PW. Handbook of Pediatric Dentistry, Mosby Elsevier $3^{\text {rd }}$ ed. 2008. p. 221-3.

8. Syarif W. Mikrodontia Insisif Lateral Sebagai Salah Satu Manifestasi Oral Penderia Sindrom Down Tipe Mosaik dan Penuh. MKB XLI 2009;41(1):32-35.

9. Desai SS. Down syndrome: A review of literature. Oral Surgery, Oral Medicine, Oral Pathology, Oral Radiology and Endodontology 2007;84(3):279-85.

10. Sjarif W. Deciduous teeth eruption in full and mosaic type of Down's syndrome patient. Maj
Ked Gigi (Dent J) 2005;38(4):183-184.

11. Bhowate R, Dubey A. Dentofacial changes and oral health status in mentally challenged children. J Indian Soc Pedod Prev Dent. 2005;23:71-3.

12. Asokan S, Muthu MS, Sivakumar N. Oral findings of Down syndrome children in Chennai city, India. Indian J Dent Res 2008;19:230-5.

13. Tongkoom S. The prevalence of dental anomalies in the primary dentition of Chinese children. Publisher: Open Dissertation Press. 1994.

14. Ezoddini AF, Sheikhha MH, Ahmadi H. Prevalence of dental developmental anomalies: A radiographic study. Community Dent Health. 2007 Sep;24(3):140-4.

15. Laskaris G. Color atlas of oral diseases in children and adolescents. New York: 2000. P. 2-3.

16. Shafer L, Hine. A Textbook of oral pathology $4^{\text {th }}$ ed. Philadephia: WB.Saunders Co., 2000. p. 38-47.

17. Tarek M. The Baby with Down Syndrome. ASJOG Vol. 2 September 2005. p. 362-5.

18. Ford D. Children with Down Syndrome. Paediatric Dentistry 2009. P. 1-6. 